\title{
Identification of circulating long non-coding RNA GAS5 as a potential biomarker for non-small cell lung cancer diagnosis
}

\author{
QIAN TAN ${ }^{1,2^{*}}$, JIANGCHENG ZUO ${ }^{1,3^{*}}$, SHILI QIU ${ }^{1,2}$, YALAN YU ${ }^{1,2}$, HU ZHOU $^{1,2}$, NANDI LI $^{1,2}$ \\ HUI WANG ${ }^{1,4}$, CHUNZI LIANG ${ }^{1,2}$, MINGXIA YU ${ }^{1,2}$ and JIANCHENG TU ${ }^{1,2}$ \\ ${ }^{1}$ Department of Laboratory Medicine, Clinical Laboratory Medicine and Center for Gene Diagnosis, \\ Zhongnan Hospital of Wuhan University; ${ }^{2}$ School of Laboratory Medicine, Hubei University of \\ Traditional Chinese Medicine, Wuhan; ${ }^{3}$ Department of Laboratory Medicine, Maternal \\ and Child Health Hospital of Yiling, Yichang; ${ }^{4}$ Department of Laboratory Medicine, \\ Central Hospital of Wuhan, Wuhan, Hubei, P.R. China
}

Received January 20, 2017; Accepted March 16, 2017

DOI: 10.3892/ijo.2017.3925

\begin{abstract}
Non-small cell lung cancer (NSCLC) is one of the most malignant cancers in the world. Early diagnosis of NSCLC has become especially important for patient treatment and prognosis. Increasing evidence suggest that long non-coding RNA GAS5 plays vital roles in cancer proliferation and differentiation in NSCLC. However, its clinical value in the diagnosis of NSCLC is unclear. The objective of this study was to evaluate the importance of circulating GAS5 as a biomarker for NSCLC diagnosis. In our study, quantitative real-time PCR (QRT-PCR) was applied to detect the GAS5 expression level in 80 pairs of cancer tissues and 57 pairs of plasma samples of NSCLC patients. Further analysis was performed to study the differential expression of circulating GAS5 in 111 NSCLC patients and 78 healthy controls in our study. The results showed that GAS5 decreased in NSCLC tissues compared to noncancerous tissues $(\mathrm{P}<0.001)$. Furthermore, the GAS5 expression level was statistically declined in early stage of NSCLC before surgery compared with healthy controls $(\mathrm{P}<0.05)$ and sharply increased in postoperative groups $(\mathrm{P}=0.026)$. ROC curve analysis for early stage of NSCLC with the combination of GAS5, CEA and CA199 showed that the area under the ROC curve (AUC) was 0.734 (95\% CI, 0.628-0.839; $\mathrm{P}<0.0005)$. In conclusion, circulating GAS5 could be functioned as a potential combined biomarker for screening NSCLC and patient monitoring after surgical treatment.
\end{abstract}

Correspondence to: Dr Jiancheng Tu, Department of Laboratory Medicine, Clinical Laboratory Medicine and Center for Gene Diagnosis, Zhongnan Hospital of Wuhan University, 169 Donghu Road, Wuhan 430071, Hubei, P.R. China

E-mail: jianchengtu@whu.edu.cn

Key words: non-small cell lung cancer, long non-coding RNA, plasma, GAS5, biomarker

\section{Introduction}

Lung cancer is one of the common malignant cancers in China with the highest mortality, constituting $18 \%$ of all cancer-related deaths (1). According to the American Cancer Society (ACS), it is estimated that non-small cell lung cancer (NSCLC) accounts for $27 \%$ of all male cancer deaths and $26 \%$ of all female cancer deaths in 2016 (2). NSCLC includes lung adenocarcinoma (LAD), lung squamous carcinoma (LSCLC) and large cell lung cancer (LCLC) which accounts for $\sim 85 \%$ of lung cancer (3). The development of NSCLC in cancer surgeries, radiotherapy, and anticancer drugs has become more rapid recently. However, the 5-year survival rate of the NSCLC patients still remains low, at $16.6 \%$. It may be caused by the cancer cell invasion and the presence of metastatic disease that is not apparent at the time of surgery $(4,5)$. Therefore, it is urgent to exploit the underlying mechanisms to identify the altered gene expression during the tumor development and establishing new biological biomarker with high sensitivity and specificity to improve the early diagnosis and treatment of NSCLC.

According to the ENCODE Consortium, $70 \%$ of the human genome has been transcribed for non-coding RNA molecules (6). Non-coding RNAs were previously considered as transcriptional noise and now they have been proved to have functional roles in structure, catalysis and regulation. Based on the transcript size, non-coding RNAs are classified into two major groups: small non-coding RNAs (sncRNA, <200 bp) and long non-coding RNAs (lncRNA, $>200$ bp) (7). MicroRNAs (miRNAs), representatives of small non-coding RNAs, are a group of short, single-stranded RNA molecules that have been confirmed to have great significance in numerous human cancers (8-11). Long non-coding RNAs (lncRNAs) are evolutionarily conserved non-coding RNAs with low expression level and no protein-coding capacity $(12,13)$. Accumulating studies have demonstrated that cellular functions of lncRNAs include the regulation of cell proliferation and differentiation or cancer progression and invasion, through which they may play important roles in multiple cancers $(14,15)$. The potential regulation pattern 
of lncRNAs to modulate the expression of associated genes may be at transcriptional, post-transcriptional and epigenetic levels (16). In recent years, accumulating studies have concluded that lncRNA dysregulation played a vital role in the development and progression of NSCLC $(17,18)$. Moreover, researchers have found that lncRNAs can be stably detected in plasma or even urine for earlier diagnosis (19-22). Due to the limited sensitivity and specificity of traditional tumor biomarkers for early stage NSCLC such as carcinoembryonie antigen (CEA), squamous cell carcinoma (SCC), neuron specific enolase (NSE) and cytokeratin 19 fragments (CA211) $(23,24)$, it becomes essential to screen for other alternative molecules functioning as diagnostic, prognostic and predictive biomarkers for NSCLC.

The IncRNA growth arrest-specific transcript 5 (GAS5) has been reported to be associated with proliferation and apoptosis of NSCLC (25), implying that it may serve as a new biomarker for NSCLC patient diagnosis. Our study here mainly focused on the circulating IncRNA expression in NSCLC patient tissues and plasma to further verify its diagnostic and prognostic value in NSCLC. The results showed that the expression levels of GAS5 were significantly downregulated in NSCLC tissues and the lower expression level has correlated with tumor size of NSCLC patients. We further ascertained its contribution in plasma and found that GAS5 was differentially expressed in early NSCLC plasma and the levels changed with surgery. Moreover, its expression level was negatively linked to CEA and CA199. These data might imply that circulating GAS5 can not only serve as a diagnosis biomarker for earlier NSCLC, but is also valuable in assessment for the postoperative condition of NSCLC.

\section{Materials and methods}

Tissue samples. Eighty NSCLC tissues and their morphologically normal tissues (located $>3 \mathrm{~cm}$ away from the tumor) utilized in this study were obtained from patients with NSCLC (59 men and 21 women; mean age, 61 \pm 15 ) who underwent surgical resection without any therapy in Zhongnan Hospital of Wuhan University between October 2014 and January 2016. All fresh tissue specimens were snap-frozen in liquid nitrogen and stored at $-80^{\circ} \mathrm{C}$ until total RNA extraction.

Plasma samples. Whole blood samples of 111 patients ( 86 men and 25 women; mean age 52 \pm 10 ) with NSCLC were recruited before surgery during the same period, including 55 patients whose tissue samples had been collected. Moreover, 57 paired postoperative blood samples were obtained $\sim 1$ month after surgery. Additionally, 78 healthy controls (52 men and 26 women; mean age, $55 \pm 10$ ) were randomly collected from the Medical Examination Center at the same stage without any cancers and other health problems. All plasma samples were isolated from peripheral blood specimens in ethylene diamine tetraacetic acid (EDTA) anti-coagulation tubes followed with a two-step centrifugation protocol to fully spin down the blood cells $\left(2000 \mathrm{~g}\right.$ for $5 \mathrm{~min}$ at $4^{\circ} \mathrm{C}, 12,000 \mathrm{~g}$ for $5 \mathrm{~min}$ at $4^{\circ} \mathrm{C}$ ). Then, they were stored at $-80^{\circ} \mathrm{C}$ until use.

Data collection. Clinical characteristics of these patients including sex, age, smoking history, tumor traditional biomarker
Table I. Correlation clinicopathological factors and GAS5 level $\left(2^{-\triangle C T}\right)$ in NSCLC patients.

\begin{tabular}{|c|c|c|c|c|}
\hline Variable & Nos. & GAS5-low ${ }^{a}$ & GAS-high & P-value \\
\hline Gender & & & & 0.204 \\
\hline Male & 59 & 32 & 27 & \\
\hline Female & 21 & 8 & 13 & \\
\hline Age (years) & & & & 0.740 \\
\hline$\leq 60$ & 41 & 19 & 22 & \\
\hline$>60$ & 39 & 21 & 18 & \\
\hline Smoking (years) & & & & 0.075 \\
\hline Never & 24 & 9 & 15 & \\
\hline Ever & 56 & 31 & 25 & \\
\hline Tumor size $(\mathrm{cm})$ & & & & $0.026^{\mathrm{c}}$ \\
\hline$\leq 3$ & 21 & 7 & 14 & \\
\hline$>3$ & 59 & 33 & 26 & \\
\hline Histological & & & & 0.109 \\
\hline I & 38 & 16 & 22 & \\
\hline II & 13 & 5 & 8 & \\
\hline III & 29 & 19 & 10 & \\
\hline T-stage & & & & 0.319 \\
\hline $\mathrm{T} 1$ & 20 & 7 & 13 & \\
\hline $\mathrm{T} 2$ & 39 & 20 & 19 & \\
\hline $\mathrm{T} 3$ & 11 & 6 & 5 & \\
\hline $\mathrm{T} 4$ & 10 & 7 & 3 & \\
\hline $\begin{array}{l}\text { Regional lymph } \\
\text { nodes }\end{array}$ & & & & 0.592 \\
\hline N0 & 50 & 23 & 27 & \\
\hline $\mathrm{N} 1$ & 8 & 4 & 4 & \\
\hline $\mathrm{N} 2$ & 22 & 13 & 9 & \\
\hline
\end{tabular}

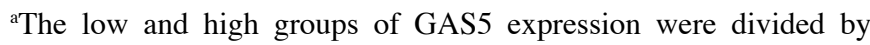
median relative expression level. ${ }^{\text {b}}$ Two-sided Chi-square test.

Table II. The plasma GAS5 level alteration among stages of NSCLC.

\begin{tabular}{lcc}
\hline Group & $-\Delta \Delta \mathrm{Ct}$ & Percentage (\%) $^{\mathrm{a}}$ \\
\hline Stage I vs. stage II & 0.06697 & 4.536 \\
Stage I vs. stage III & 0.48683 & 28.64 \\
Stage II vs. stage III & 0.41986 & 25.25 \\
Stage I+II vs. stage III & 0.46557 & 27.58 \\
Stage I vs. stage II+III & 0.32546 & 19.64 \\
\hline
\end{tabular}

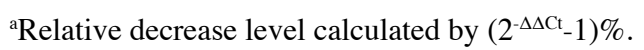

levels (CEA, NSE, SCC, CA211, CA199, CA125), tumor size, lymph node metastasis and histological grade were collected (Tables I and II). The basic information such as gender, age, CEA, CA199 and CA125 of healthy controls was gathered from LIS of hospital clinical laboratory for further data analysis. 
A

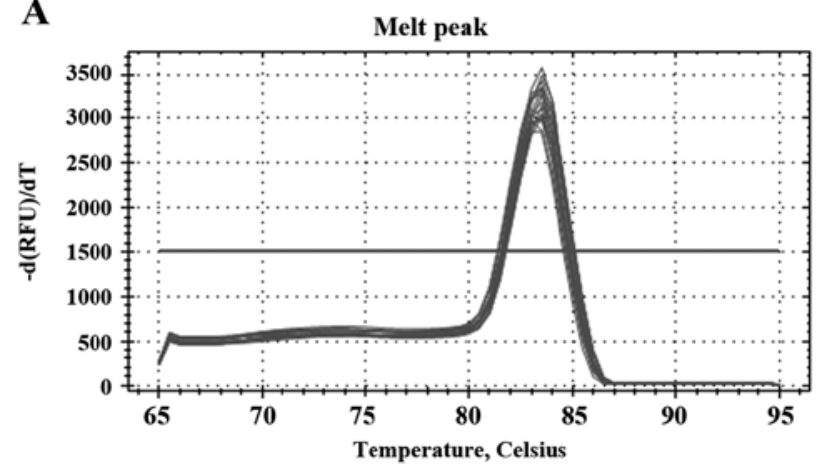

B

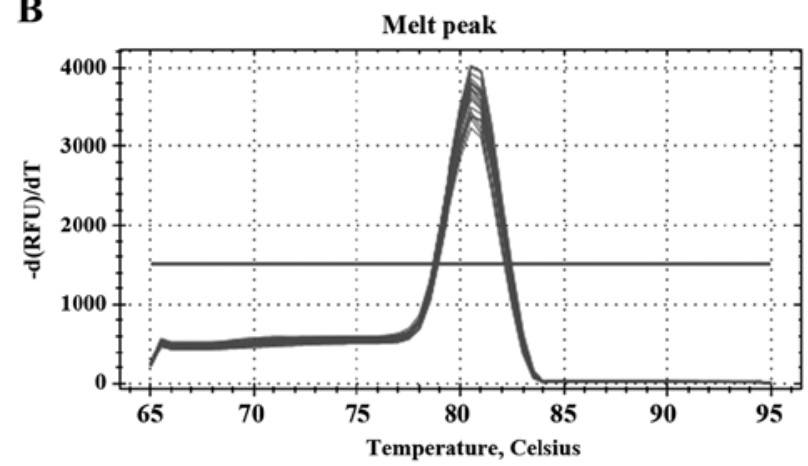

Figure 1. The figures of melt peak in melting curve analysis. (A) Endogenous control, GAPDH; (B) GAS5.

Cell lines and culture. Four NSCLC cell lines (including NSCLC cell lines H1299, 95-D and ADC cell lines A549, SPC-A-1) and human embryonic lung fibroblast (HELF) were kindly provided by Public Health of Wuhan University. All cell lines were cultured in DMEM medium (Hyclone, China) added with $10 \%(\mathrm{v} / \mathrm{v})$ fetal bovine serum, $100 \mathrm{IU} / \mathrm{ml}$ penicillin and streptomycin $(100 \mathrm{U} / \mathrm{ml})$, then they were incubated at $37^{\circ} \mathrm{C}$ in a humidified chamber with $5 \%(\mathrm{v} / \mathrm{v}) \mathrm{CO}_{2}$. The cellular RNA was extracted when all the cells were at the best state and repeated three times.

Ethics approval. All the patients signed the informed consent form. The use of the tissues and plasma samples for the experiment was approved by the Ethics Committee of Zhongnan Hospital of Wuhan University (Wuhan, China).

Total RNA isolation, $R T$ and QRT-PCR. For tissues and cell lines, the total RNA was extracted using TRIzol reagent (Invitrogen, CA, USA) according to the manufacturer's instructions. For plasma samples, it was extracted from $300 \mu \mathrm{l}$ cell-free plasma using blood/liquid sample Total RNA Rapid Extraction kit (spin-column) (Bioteke, Beijing, China) and eluted with $30 \mu$ l RNase-free water eventually. All the RNA was then transcribed to cDNA at once.

The QRT-PCR assay was conducted to detect the level of RNA transcripts. For reverse transcription (RT) reaction, the reaction mixture $(20 \mu \mathrm{l})$ for tissues and cell lines containing $1 \mu \mathrm{g}$ total RNA was reversely transcribed to cDNA by using PrimeScript RT reagent kit with gDNA Eraser (Takara, Dalian, China), while $7 \mu \mathrm{l}$ plasma RNA was used in the RT reaction $\left(20 \mu \mathrm{l}\right.$ ), followed the protocol of $42^{\circ} \mathrm{C}$ for $2 \mathrm{~min}$, then $37^{\circ} \mathrm{C}$ for $15 \mathrm{~min}$ and $85^{\circ} \mathrm{C}$ for $5 \mathrm{sec}$. Then all cDNA samples were detected immediately by QRT-PCR using the SYBR ${ }^{\circledR}$ Premix Ex Taq ${ }^{\mathrm{TM}}$ II real-time PCR kit (Takara) in a $20-\mu 1$ reaction volume, which contained $10 \mu \mathrm{l}$ of SYBR-Green master PCR mix, $0.8 \mu \mathrm{l}$ each of forward and reverse primers, $2 \mu \mathrm{l}$ of diluted cDNA template, and appropriate amounts of sterile distilled water. The cycling conditions were initial denaturation at $95^{\circ} \mathrm{C}$ for $5 \mathrm{~min} ; 40$ cycles of denaturation at $95^{\circ} \mathrm{C}$ for $30 \mathrm{sec}$, annealing at $62.5^{\circ} \mathrm{C}$ for $30 \mathrm{sec}$, and elongation at $72^{\circ} \mathrm{C}$ for $30 \mathrm{sec}$. Given that the level of glyceraldehyde-phosphate dehydrogenase (GAPDH) mRNA was found to be relatively stable in plasma $(26,27)$, we chose GAPDH as the endogenous control for data normalization to determine the relative expression of the target genes. The sequence of PCR primers are as follows: GAS5, forward, 5'-GTGTGGCTCTGGAT AGCAC-3'; reverse, 5'-ACCCAAGCAAGTCATCCATG-3'. GAPDH, forward, 5'-GGTCTCCTCTGACTTCAACA-3'; reverse, 5'-GTGAGGGTCTCTCTCTTCCT-3'. The reaction conditions were set according to the kit instructions. After completion of the reaction, the amplification curve and melting curve were analyzed to measure the specificity of the amplified products.

Statistical analysis. The relative expression of GAS5 was calculated using the comparative cycle threshold $(\mathrm{Ct})$ method $\left(2^{-\Delta \mathrm{Ct}}\right)$. Samples with a $\mathrm{Ct}>40$ were considered as negative. All statistical analyses were performed using the Statistical Product and Service Solutions (SPSS) 17.0 software (SPSS, Chicago, IL, USA). Data analysis was performed for pairs of tissues and plasma samples by using paired-sample t-test. The analysis between NSCLC plasma and controls was applied by using independent two-tailed t-test. Two-sided Chi-square test and one-way ANOVA were used to assess the association between the expression level and clinicopathological factors. A receiver operating characteristic (ROC) curve was applied to evaluate the diagnostic value. $\mathrm{P}<0.05$ was considered statistically significant.

\section{Results}

Cloning and sequencing of $q R T-P C R$ products. The qRT-PCR products of GAS5 and GAPDH were purified using the AxyPrep DNA Gel Extraction kit (Axygen, USA) and then were cloned into the PMD 19-T vector (Takara). The melting curve analysis (Fig. 1) and their PCR products sequence results were available as expected, which were completely consistent with the entries from the NCBI database (Fig. 2).

GAS5 expression level in NSCLC tissues and cell lines. To further validate the importance of GAS5 in NSCLC, its expression level was detected in 80 pairs of NSCLC tissue samples (including 40 ADC, 36 SCC and 4 LSLC) and corresponding normal tissues by using quantitative real-time PCR. The results showed that GAS5 was distinctly decreased in NSCLC tissues $(\mathrm{P}<0.001)$ (Fig. 3A). Waterfall plot further demonstrated that GAS5 was reduced $\geq 3$-fold in $46.3 \%$ (37/80) of the NSCLC patients (Fig. 3B). Data analysis showed the GAS5 expression 
A

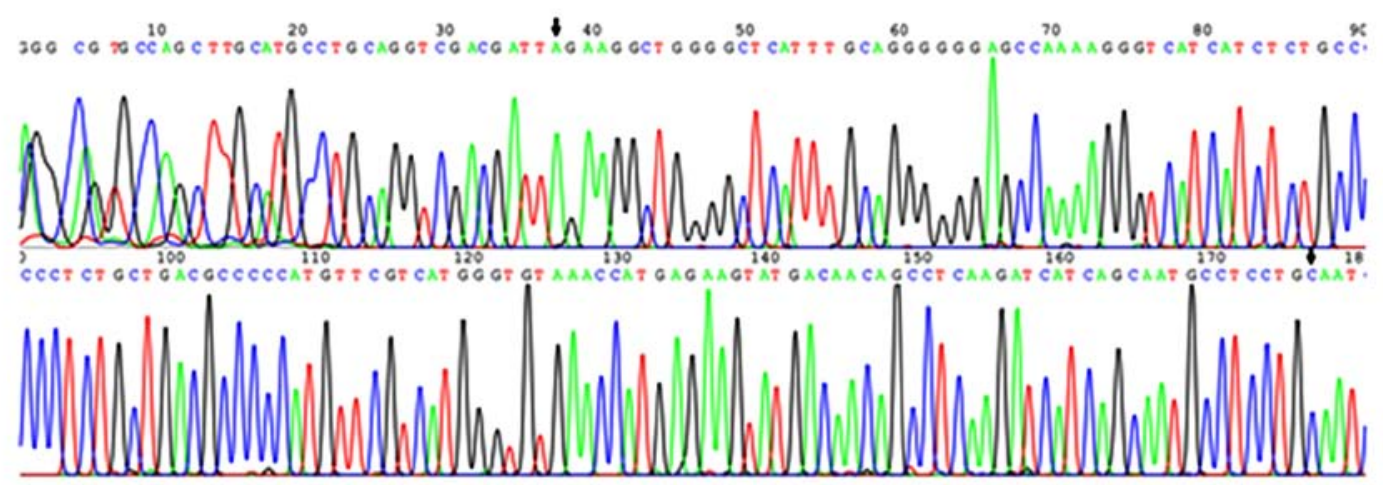

B

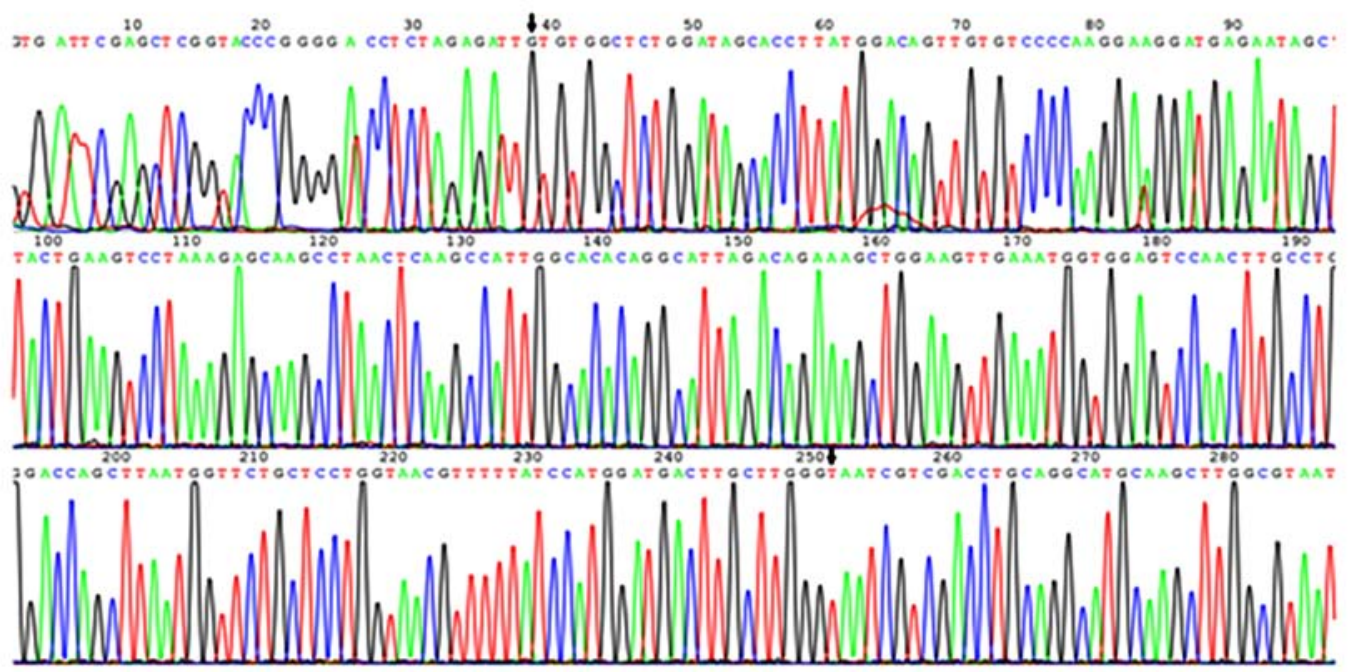

Figure 2. Sequencing results of qRT-PCR products. (A) Endogenous control, GAPDH; (B) GAS5.

A

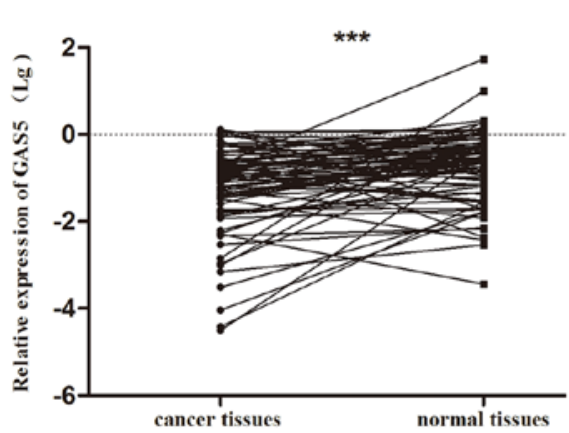

C

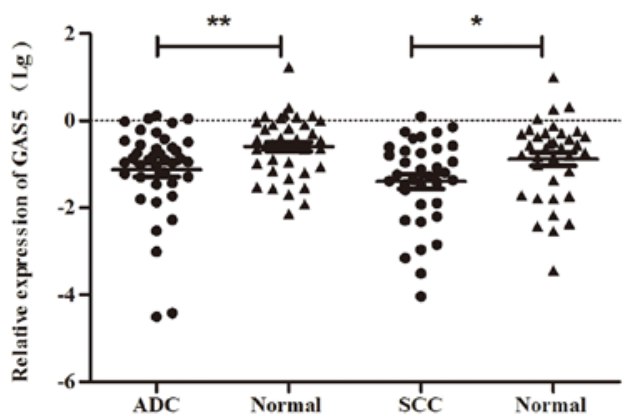

B

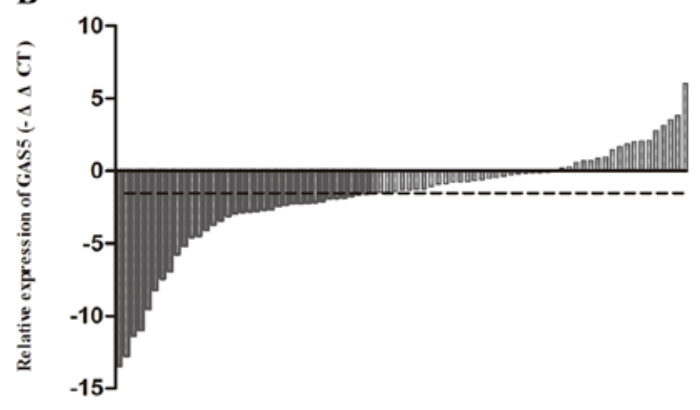

D

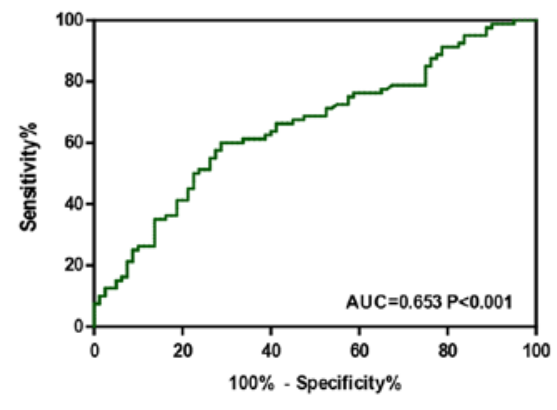

Figure 3. GAS5 expression levels were detected by using QRT-PCR in NSCLC patients. (A) GAS5 was distinctly downregulated in 80 NSCLC tissues compared to noncancerous. (B) Waterfall plot shows that GAS5 was downregulated in $46.3 \%$ (37/80) of NSCLC tissues by $\geq 3$-fold, $-\Delta \Delta C \mathrm{CT}=-\left[\left(\mathrm{CT}_{\mathrm{GASS}}-\mathrm{CT}_{\mathrm{GAPDH}}\right)\right.$ of NSCLC - $\left(\mathrm{CT}_{\mathrm{GS} 5}-\mathrm{CT}_{\mathrm{GAPDH}}\right)$ of NT]. NT, non-tumorous tissues of NSCLC. (C) Expression levels of GAS5 between the two subtypes of NSCLC $\left(\mathrm{N}_{\mathrm{ADC}}=40\right.$ and $\mathrm{N}_{\mathrm{SCC}}=36$ ). (D) The ROC curve of GAS5 expression levels in tissues for NSCLC (AUC $=0.653,95 \% \mathrm{CI}, 0.568-0.738, \mathrm{P}<0.001$ ). The expression levels were calculated using $\operatorname{Lg}\left(2^{-\Delta C T}\right)$. All data were analyzed by Student's t-test, ${ }^{*} \mathrm{P}<0.05,{ }^{* * *} \mathrm{P}<0.01,{ }^{* * * *} \mathrm{P}<0.001$. 


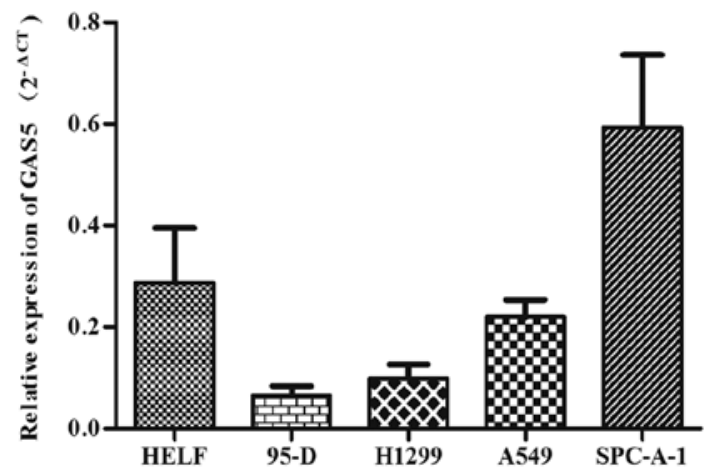

Figure 4. GAS5 expression levels were detected by QRT-PCR in NSCLC cell lines. The expression levels were calculated using $2^{-\Delta C T}$.

level presented a similar trend and declined both in $\mathrm{ADC}$ and SCC $(\mathrm{P}<0.05)$ (Fig. 3C). In addition, the ROC curve illustrated strong separation between the tumor tissues and control group, with an area under curve (AUC) of 0.653 (95\% CI, 0.568-0.738; $\mathrm{P}<0.001$ ) (Fig. 3D).

We further explored its relative expression in four NSCLC cell lines (H1299, 95-D, A549, SPC-A-1) and human embryonic lung fibroblast (HELF) by QRT-PCR, and results indicated a lower expression of GAS5 in H1299, 95-D, A549 cell lines compared with HELF cell line except for SPC-A-1 cell line (Fig. 4). Among the three NSCLC cell lines, GAS5 decreased the most in 95-D and H1299 cell lines.
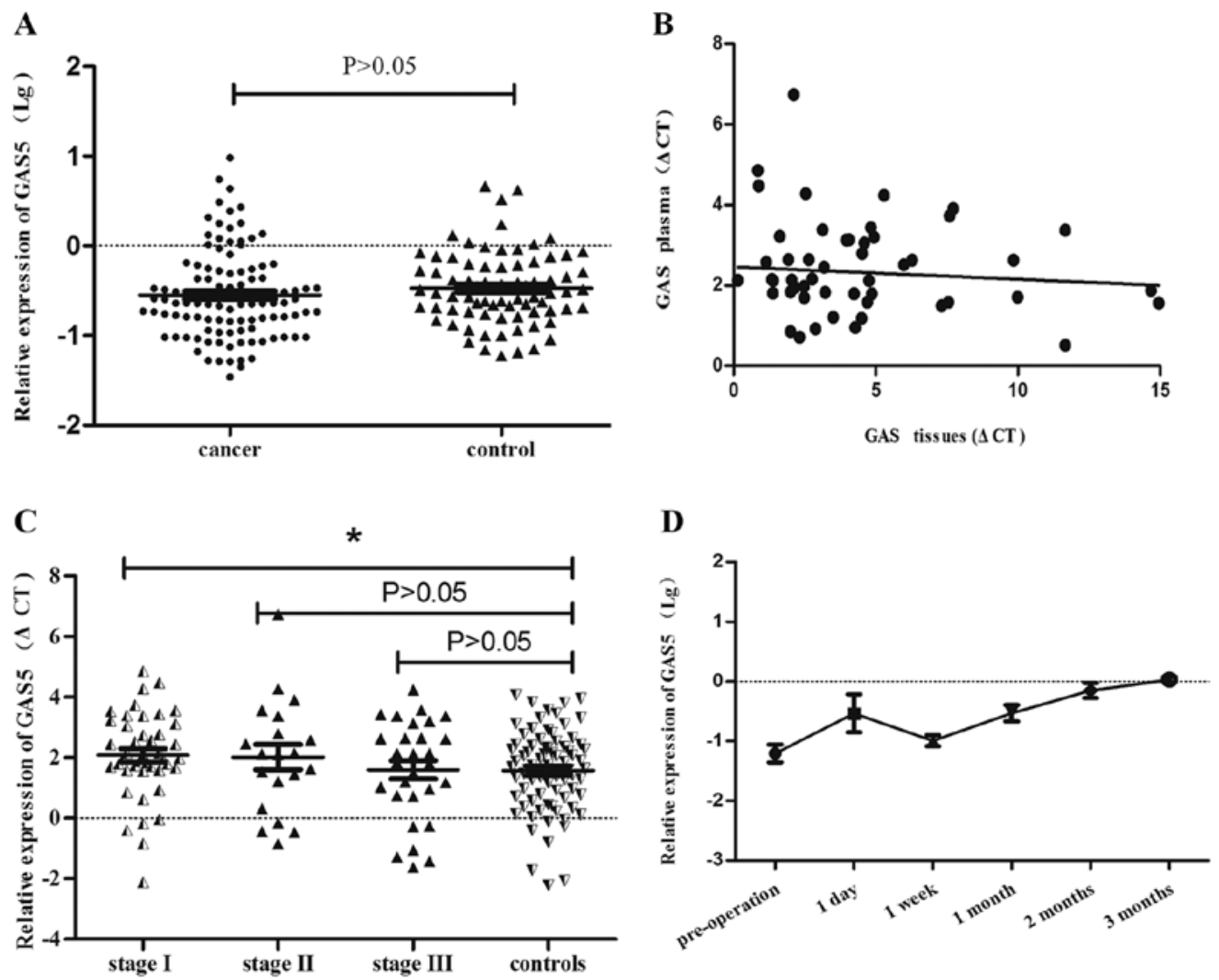

Figure 5. (A) The expression levels of plasma GAS5 in NSCLC patients $(\mathrm{n}=111)$ and healthy controls $(\mathrm{n}=78)$. There was no significant difference as determined by RT-PCR ( $\mathrm{P}=0.190)$. (B) Linear correlation plot showed a weak connection of GAS5 expression between tumor tissues and plasma in NSCLC patients ( $\mathrm{P}>0.05)$. (C) The GAS5 expression levels was significantly downregulated in early stage plasma samples with NSCLC compared with controls ( $\mathrm{P}=0.0493)$. (D) The expression alteration of GAS5 after operation. The data were calculated using the $\operatorname{Lg}\left(2^{-\Delta C T}\right)$ method for (A) and (D), the $\Delta C T$ method for (B) and (C). 
A

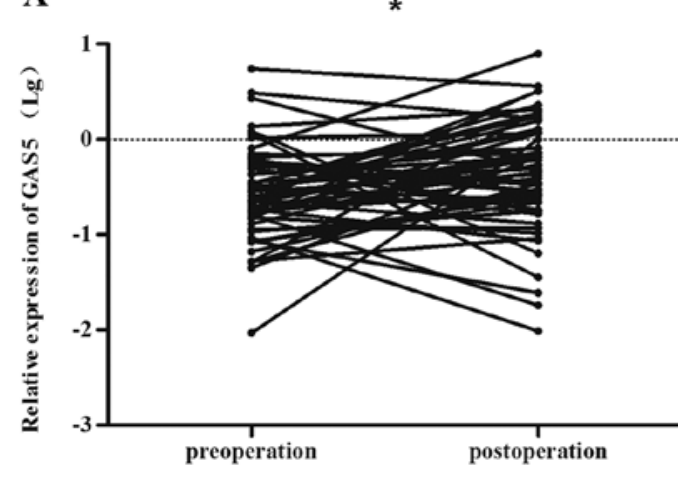

B

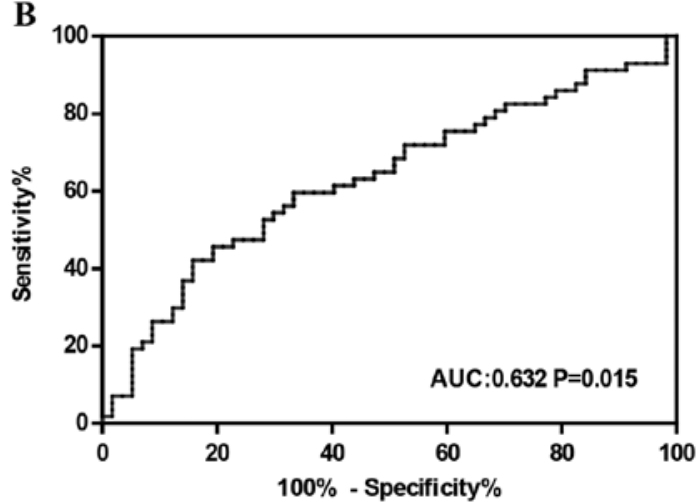

Figure 6. (A) The GAS5 expression levels were significantly upregulated in postoperative plasma samples compared with preoperation (n=57, $\mathrm{P}=0.026)$. The expression levels were calculated using the $\operatorname{Lg}\left(2^{-\Delta C T}\right)$ method. (B) The ROC curve of GAS5 expression levels in plasma (preoperation vs postoperation) for NSCLC (AUC=0.632, 95\% CI, 0.5292-0.7352; $\mathrm{P}=0.015)$.

Table III. The plasma GAS5 level alteration among stages of NSCLC and control group.

\begin{tabular}{lcc}
\hline Group & $-\Delta \Delta \mathrm{Ct}$ & ${\text { Percentage }(\%)^{\mathrm{a}}}^{\mathrm{a}}$ \\
\hline Stage I vs. C & 0.51332 & $29.94^{\mathrm{c}}$ \\
Stage II vs. C & 0.44632 & 26.61 \\
Stage III vs. C & 0.02648 & 1.819 \\
Stage I+II vs. C & 0.49205 & 28.90 \\
Stage II+III vs. C & 0.19785 & 12.82 \\
\hline
\end{tabular}

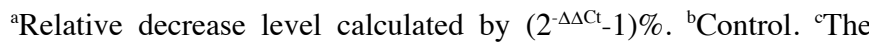
comparison has statistical significance.

Expression alteration of GAS5 after operation. We collected blood samples of 8 patients before surgery and the corresponding blood specimens after resection according to their post-operation time. Under the same treatment, the GAS5 expression level for each plasma sample was analyzed by QRT-PCR (Fig. 5D). The variation of GAS5 expression was slightly increased after one day of resection $(\mathrm{P}=0.1033)$, there was an abrupt decline after 7 days of operation $(\mathrm{P}=0.2436)$. However, as seen from the figure along with the changes of operation time, the GAS5 expression showed an obvious elevated trend starting from the seventh day. There was a statistical difference between pre-operation and post-operation plasma after 1 month $(\mathrm{P}=0.0124)$ and 2 months $\mathrm{P}=0.001)$.

Surgical assessment of GAS5 in plasma of NSCLC patients. Our study also investigated the difference in expression levels between 57 paired plasma specimens (pre-operation and postoperation samples). We found that plasma levels of circulating RNA GAS5 was significantly increased after surgical treatment compared to pre-operation $(\mathrm{P}<0.05)$ (Fig. 6A). The result suggested that circulating GAS5 in plasma could be acceptable for evaluation of NSCLC surgical resection. Further analysis of the ROC curve for post-operation was shown in Fig. 6B, with an area under curve (AUC) of 0.632 (95\% CI, 0.529-0.735; $\mathrm{P}=0.015)$. indicators with GAS5 expression level. To affirm the relation-

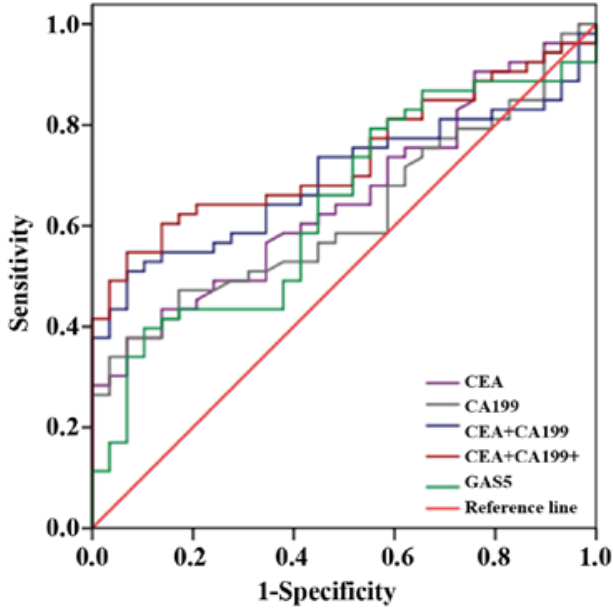

Figure 7. Receiver operating characteristic (ROC) curves for early stage with NSCLC (NSCLC plasma vs. controls).

ship of plasma GAS5 levels with clinical parameters, NSCLC patients' pathologic information including age, gender, smoking history, tumor size, TNM stage, lymphatic metastasis, differentiation, and histological classification were collected and analyzed by one-way ANOVA. As shown in Table IV, the GAS5 expression levels showed huge variability between ADC and SCC plasma samples $(\mathrm{P}<0.05)$, no differences were found among the other characteristics.

Then, to explore whether there is a connection between the patient serum index and GAS5 levels, traditional tumor makers including CEA, NSE, SCC, CA211, CA199 and CA125 were classified into normal and abnormal groups based on the criteria of diagnosis in our hospital (Table V). There were no differences among SCC, CA211 and NSE, but the GAS5 expression level had a statistical relationship both in CEA and CA199 groups $(\mathrm{P}<0.05$ and $\mathrm{P}<0.01$, respectively).

Diagnostic potential of circulating GAS5 for early NSCLC. Based on our results, we further analyzed the ROC curves of CEA, CA199 and GAS5 in early stage of NSCLC compared with controls, and we found that the combination of the three indicators possessed higher sensitivity and specificity when they were applied alone as shown in Fig. 7 and Table VI. The 
Table IV. Correlation of plasma GAS5 levels $(\Delta \mathrm{Ct})$ among clinical parameters of NSCLC patients.

\begin{tabular}{|c|c|c|c|}
\hline $\begin{array}{l}\text { Clinical } \\
\text { characteristic }\end{array}$ & $\begin{array}{c}\text { No. of }{ }^{a} \\
\text { cases }(\%)\end{array}$ & Mean \pm SEM $^{\mathrm{b}}$ & P-value \\
\hline Age (years) & & & 0.116 \\
\hline$\leq 60$ & $40(36.0)$ & $2.21 \pm 0.29$ & \\
\hline$>60$ & $71(64.0)$ & $1.69 \pm 0.18$ & \\
\hline Gender & & & 0.381 \\
\hline Female & $25(22.5)$ & $1.61 \pm 0.42$ & \\
\hline Male & $86(77.5)$ & $1.94 \pm 0.17$ & \\
\hline Smoking history & & & 0.520 \\
\hline Never & $31(28.4)$ & $1.70 \pm 0.35$ & \\
\hline Present & 78 (71.6) & $1.93 \pm 0.18$ & \\
\hline Histological & & & \\
\hline classification & & & $\mathbf{0 . 0 1 7}{ }^{\mathrm{d}}$ \\
\hline $\mathrm{ADC}$ & $51(48.1)$ & $1.41 \pm 0.21$ & \\
\hline $\mathrm{SCC}$ & $55(51.9)$ & $2.18 \pm 0.24$ & \\
\hline Tumor size $(\mathrm{cm})$ & & & 0.920 \\
\hline$\leq 3$ & $22(23.7)$ & $1.87 \pm 0.32$ & \\
\hline$>3$ & $71(76.3)$ & $1.91 \pm 0.20$ & \\
\hline T stage & & & 0.545 \\
\hline $\mathrm{T} 1$ & $22(23.7)$ & $1.87 \pm 0.32$ & \\
\hline $\mathrm{T} 2$ & $48(51.6)$ & $2.08 \pm 0.23$ & \\
\hline $\mathrm{T} 3$ & $16(17.2)$ & $1.59 \pm 0.45$ & \\
\hline $\mathrm{T} 4$ & $7 \quad(7.5)$ & $1.49 \pm 0.64$ & \\
\hline $\mathrm{N}$ stage & & & 0.457 \\
\hline No & $61(65.6)$ & $2.01 \pm 0.20$ & \\
\hline N1 & $8(8.6)$ & $2.16 \pm 0.86$ & \\
\hline $\mathrm{N} 2$ & $24(25.8)$ & $1.55 \pm 0.31$ & \\
\hline TNM stage & & & 0.344 \\
\hline I & $44(47.3)$ & $2.08 \pm 0.22$ & \\
\hline II & $20(21.5)$ & $2.02 \pm 0.42$ & \\
\hline III & $29(31.2)$ & $1.60 \pm 0.30$ & \\
\hline Differentiation & & & 0.207 \\
\hline High & $7(8.0)$ & $1.06 \pm 0.56$ & \\
\hline High-moderate & $5 \quad(5.7)$ & $2.21 \pm 0.73$ & \\
\hline Moderate & $47(53.4)$ & $1.79 \pm 0.24$ & \\
\hline Moderate-low & $11(12.5)$ & $1.19 \pm 0.49$ & \\
\hline Low & $18(20.4)$ & $2.43 \pm 0.36$ & \\
\hline $\begin{array}{l}\text { Ki67 proliferation } \\
\text { index }(\%)\end{array}$ & & & 0.646 \\
\hline$\leq 50$ & $34(50.0)$ & $1.94 \pm 0.24$ & \\
\hline$>50$ & $34(50.0)$ & $1.77 \pm 0.28$ & \\
\hline EGFR & & & 0.084 \\
\hline Normal & $16(50.0)$ & $2.06 \pm 0.31$ & \\
\hline Abnormal & $16(50.0)$ & $1.09 \pm 0.45$ & \\
\hline
\end{tabular}

a Data missing in some groups. ${ }^{\mathrm{b}}$ LncRNA expression levels were calculated using the comparative cycle threshold $(\mathrm{Ct})$ method $(\Delta \mathrm{Ct})$. 'One-way ANOVA. Bold text, statistically significant.
Table V. Relationship of plasma GAS5 levels $(\Delta \mathrm{Ct})$ among serum index of NSCLC patients.

\begin{tabular}{|c|c|c|c|}
\hline Factors & No. of cases $(\%)^{\mathrm{a}}$ & Mean \pm SEM $^{\mathrm{b}}$ & P-value \\
\hline $\mathrm{CEA}(\mu \mathrm{g} / 1)$ & & & $0.021^{\mathrm{c}}$ \\
\hline$\leq 5.0$ & $68(73.9)$ & $2.19 \pm 0.18$ & \\
\hline$>5.0$ & $24(26.1)$ & $1.27 \pm 0.39$ & \\
\hline NSE (ng/ml) & & & 0.934 \\
\hline$\leq 18.3$ & $72(92.3)$ & $1.83 \pm 0.20$ & \\
\hline$>18.3$ & $6 \quad(7.7)$ & $1.89 \pm 1.00$ & \\
\hline CA211 (ng/ml) & & & 0.657 \\
\hline$\leq 3.3$ & $14(70.0)$ & $2.38 \pm 0.31$ & \\
\hline$>3.3$ & $6(30.0)$ & $2.10 \pm 0.61$ & \\
\hline $\mathrm{SCC}(\mu \mathrm{g} / \mathrm{l})$ & & & 0.841 \\
\hline$\leq 1.5$ & $16(84.2)$ & $2.26 \pm 0.35$ & \\
\hline$>1.5$ & $3(15.8)$ & $2.42 \pm 0.14$ & \\
\hline CA125 (U/ml) & & & 0.096 \\
\hline$\leq 35$ & $79(83.1)$ & $2.08 \pm 0.18$ & \\
\hline$>35$ & $16(16.9)$ & $1.32 \pm 0.46$ & \\
\hline CA199 (U/ml) & & & $0.0008^{c}$ \\
\hline$\leq 37$ & $82(86.3)$ & $2.18 \pm 0.17$ & \\
\hline$>37$ & $13(13.7)$ & $0.54 \pm 0.51$ & \\
\hline
\end{tabular}

${ }^{a}$ Data missing in some groups. ${ }^{b}$ LncRNA expression levels were calculated using the comparative cycle threshold $(\mathrm{Ct})$ method $(\Delta \mathrm{Ct})$.

sensitivity and specificity were $\leq 86.76 \%$ and $62.62 \%$. Hence, circulating GAS5 might serve as a combined diagnostic indicator for early diagnosis of NSCLC.

Taken together, we have demonstrated that the lncRNA GAS5 level was dysregulated in NSCLC patients in the present study. Circulating GAS5 can potentially be useful for monitoring surgical treatment in NSCLC patients and has a potential as a combined biomarker for NSCLC screening. It provides a useful auxiliary diagnostic method to screen for a large number of candidate patients and increase our understanding of NSCLC pathology.

\section{Discussion}

It is well-known, early diagnosis is the main way to improve the survival rate of lung cancer patients, whereas it is still difficult at present. Single serological index including CEA, SCC, CYFRA 21-1 and NSE for the diagnostic sensitivity and specificity of lung cancer is often unsatisfactory, especially for early clinical stages (28).

The lncRNAs have recently become a research focus worldwide, as a group of RNA molecules that are longer than $200 \mathrm{nt}$ without protein-coding capacity (29). Increasing studies have revealed that lncRNAs play fundamental roles in carcinomas such as breast cancer (30), cervical cancer (31) and gastric cancer (32), or diseases such as neurological disorders (33), kidney and cardiovascular diseases (34). Due to the potential detection of lncRNAs in plasma or even urine of cancer patients, they could be applied as biomarkers for 
Table VI. Analysis of ROC curves within groups.

\begin{tabular}{lccccc}
\hline Group & AUC & $95 \%$ CI & P-value & $\%$ Se & $\% \mathrm{Sp}$ \\
\hline CEA & 0.651 & $0.534-0.768$ & 0.024 & 21.95 & 90.57 \\
CA199 & 0.622 & $0.503-0.742$ & 0.068 & 6.897 & 98.11 \\
GAS5 & 0.638 & $0.515-0.760$ & 0.223 & 42.31 & 77.78 \\
CEA+CA199 & 0.694 & $0.582-0.805$ & 0.004 & 55.17 & 73.58 \\
CEA+CA199+GAS5 & 0.734 & $0.628-0.839$ & $<0.0005$ & 86.76 & 62.62 \\
\hline
\end{tabular}

AUC, area under the receiver operating characteristic curves; Se, sensitivity; Sp, specificity.

the earlier diagnosis of cancers. For example, dysregulated long non-coding RNA prostate cancer antigen 3 (PCA3) promotes prostate cancer cell proliferation possibly through the AR signal pathway. Also, urine PCA3 can be used as a non-invasive method for early diagnosis of prostate cancer $(35,36)$. Another study showed that plasma MALAT-1 was correlated with liver damage and combination of MALAT1, AFP and PIVKAII can improve the diagnostic value of HCC (37). Moreover, according to the study of Li et al, linc00152 could be detected in plasma of GC patients as a result of exosome protection (38). These findings further confirmed that IncRNAs can serve as molecule biomarkers for cancer diagnosis and prognosis.

Our target gene GAS5 was originally isolated from a subtraction cDNA library and was expressed relatively higher in growth arrest cells (39). It is located at 1q25.1 containing 12 exons with only a short open reading-frame that cannot encode a functional protein. The high expression abundance of GAS5 may be explained by the interaction between rapamycin (mTOR) pathway (40) and the nonsensemediated decay (NMD) pathway (41). Plenty of experiments have demonstrated that overexpression of GAS5 can induce apoptosis and reduce the rate of progression in S phase (42). Because of the existence of apoptosis in the physiological and pathological processes, the molecular mechanisms of GAS5 in various cancers was uncovered in different aspects. For instance, downregulated GAS5 in NSCLC tissues is able to promote cell proliferation and reduce apoptosis (25).

Why circulating lncRNAs could be detected in plasma may be that they are packaged in some microparticles such as exomes, microvesicles and apoptotic bodies (27). Long non-coding RNAs H19, HOTAIR and MALAT1 were reported to stably exist in plasma (43). A recent study of our laboratory showed that the detection level of GAS5 and GAPDH did not change much when the whole blood samples were at $4^{\circ} \mathrm{C}$ for $24 \mathrm{~h}$ before plasma pheresis. Also, plasma specimens can be stored at $-80^{\circ} \mathrm{C}$ for at least one month. Moreover, they are relatively stable when the plasma samples were treated with freeze-thaw cycles (44). These findings agree with our results to a certain degree.

How the circulating lncRNAs in blood are generated and the mechanism for them to provide long-term circulation in the bloodstream remain unclear. The most popular explanation is that, as a kind of circulating nucleic acid (CNA), it may stem from the self-secretion, cracking apoptosis and necrosis of tumor cells $(45,46)$. Under the speculation, our results showed plasma GAS5 levels were significantly downregulated in early stage of NSCLC patients compared with healthy controls $(\mathrm{P}<0.0493)$, while tissue GAS5 levels were downregulated in advanced stage, others studying other lncRNAs in gastric cancer (GC) have found similar results. Shao et al demonstrated that tissue lncRNA AA174084 levels were significantly downregulated in both early and advanced stage of GC patients. However, the plasma lncRNA AA174084 levels were downregulated in early stage of GC compared to advanced stage. Also, they mentioned that the increase of gastric juice AA174084 level in patients who had GC (especially those who had early GC) did not indicate that the AA174084 level in gastric juice will decrease along with the increasing severity of GC (27). Yang et al also found that tissue lncRNA $\mathrm{ABHD}_{11}$-AS1 levels were upregulated in GC, while gastric juice lncRNA $\mathrm{ABHD}_{11}$-AS1 levels were only significantly upregulated in early gastric cancer (EGC) (47). All the results indicated that the correlation of lncRNA levels between tissues and plasma might be affected by other reasons. However, Chen and colleagues mentioned that CNAs may be also correlated tightly with the immune response, and it was not just a result of cancer but may actively contribute to cancer defense (48). The strong separation between LAD and SCC patient plasma $(\mathrm{P}=0.017)$ could be explained by the difference mechanism of CNAs releasing to bloodstream. However, further research is needed to explain this phenomenon.

Many studies have presented that the expression alteration of other lncRNAs of cancer patients who underwent surgery could reflect surgical assessment and tumor dynamics. Han et al discovered that lower plasma GAS5 level was observed in breast cancer patients with a high Ki67 proliferation index before surgery and patients with a positive lymph node metastasis state after surgery (44). Yang et al found that circulating H19 levels declined markedly in gastric cancer patients after surgery and that lncRNAs may be protected by exosomes (49). Zhang et al found that the downregulation of circulating H19 levels in breast cancer patients after surgery can monitor the patients condition (50). In our study, the exploration of the alteration for GAS5 level over time after surgery better confirmed our hypothesis that surgical resection had important effects on GAS5 expression level. Our data showed plasma GAS5 statistically elevated in postoperative NSCLC patients after resection $(\mathrm{P}=0.026)$, indicating that IncRNA GAS5 might have the potential to assess the surgical effects for NSCLC patient. Thus, the operation may stimulate cells to release an amount of IncRNA to the circulation. 
There commonly exist several EGFR mutations ( 63.1\%) in Chinese NSCLC patients in the locations of 18, 19 and 21 exons. It has been reported that EGFR mutation can lead to drug resistance and poor prognosis of NSCLC patients $(51,52)$. Recent studies explored a series of lncRNAs dysregulated in EGFR exon deletion in lung adenocarcinoma that played critical roles by regulating neighboring molecules associated with EGFR-TKIs resistance $(53,54)$. Our result found that a low level of plasma GAS5 has a tendency for patients with EGFR mutation ( $\mathrm{P}=0.084)$, which was consistent with the outcomes in EGFR-TKI sensitive and resistant cell lines discovered by Dong et al (55).

We further found that GAS5 level has tight relationship with CEA and CA199 ( $\mathrm{P}=0.017$ and $\mathrm{P}=0.001$ respectively). Further analysis by ROC curves showed that the combination of circulating GAS5 levels with CEA and CA199 is considered to be more advantageous for the diagnosis of NSCLC (Table IV).

However, there are some research limitations in our study, including insufficient sample size for advanced stage, the missing data of some patients, failure in further mechanism research. Therefore, more studies should be carried out for the biological role of circulating lncRNAs.

\section{Acknowledgements}

This study was supported by the National Basic Research Program of China (973 Program) (2012CB720605).

\section{References}

1. Haaland B, Tan PS, de Castro G Jr and Lopes G: Meta-analysis of first-line therapies in advanced non-small-cell lung cancer harboring EGFR-activating mutations. J Thorac Oncol 9: 805-811, 2014.

2. Siegel RL, Miller KD and Jemal A: Cancer statistics, 2016. CA Cancer J Clin 66: 7-30, 2016.

3. Ettinger DS, Akerley W, Bepler G, Blum MG, Chang A, Cheney RT, Chirieac LR, D'Amico TA, Demmy TL, Ganti AK, et al; NCCN Non-Small Cell Lung Cancer Panel Members: Non-small cell lung cancer. J Natl Compr Canc Netw 8: 740-801, 2010.

4. Wu Y, Liu H, Shi X, Yao Y, Yang W and Song Y: The long non-coding RNA HNF1A-AS1 regulates proliferation and metastasis in lung adenocarcinoma. Oncotarget 6: 9160-9172, 2015.

5. Koudelakova V, Kneblova M, Trojanec R, Drabek J and Hajduch M: Non-small cell lung cancer - genetic predictors. Biomed Pap Med Fac Univ Palacky Olomouc Czech Repub 157: 125-136, 2013.

6. Han Li C and Chen Y: Small and long non-coding RNAs: Novel targets in perspective cancer therapy. Curr Genomics 16 319-326, 2015

7. Zhang A, Zhang J, Kaipainen A, Lucas JM and Yang H: Long non-coding RNA: A newly deciphered 'code' in prostate cancer. Cancer Lett 375: 323-330, 2016.

8. Lu J, Getz G, Miska EA, Alvarez-Saavedra E, Lamb J, Peck D, Sweet-Cordero A, Ebert BL, Mak RH, Ferrando AA, et al MicroRNA expression profiles classify human cancers. Nature 435: 834-838, 2005.

9. Jin Z, Guan L, Song Y, Xiang GM, Chen SX and Gao B: MicroRNA-138 regulates chemoresistance in human non-small cell lung cancer via epithelial mesenchymal transition. Eur Rev Med Pharmacol Sci 20: 1080-1086, 2016.

10. Zhu K, Ding H, Wang W, Liao Z, Fu Z, Hong Y, Zhou Y, Zhang CY and Chen X: Tumor-suppressive miR-218-5p inhibits cancer cell proliferation and migration via EGFR in non-small cell lung cancer. Oncotarget 7: 28075-28085, 2016.

11. Liu H: MicroRNAs in breast cancer initiation and progression. Cell Mol Life Sci 69: 3587-3599, 2012.

12. Schmitz SU, Grote P and Herrmann BG: Mechanisms of long noncoding RNA function in development and disease. Cell Mol Life Sci 73: 2491-2509, 2016.
13. Tantai J, Hu D, Yang Y and Geng J: Combined identification of long non-coding RNA XIST and HIF1A-AS1 in serum as an effective screening for non-small cell lung cancer. Int J Clin Exp Pathol 8: 7887-7895, 2015

14. Esteller M: Non-coding RNAs in human disease. Nat Rev Genet 12: 861-874, 2011.

15. Gibb EA, Brown CJ and Lam WL: The functional role of long non-coding RNA in human carcinomas. Mol Cancer 10: 38, 2011.

16. Kaplan R, Luettich K, Heguy A, Hackett NR, Harvey BG and Crystal RG: Monoallelic up-regulation of the imprinted H19 gene in airway epithelium of phenotypically normal cigarette smokers. Cancer Res 63: 1475-1482, 2003.

17. Ricciuti B, Mencaroni C, Paglialunga L, Paciullo F, Crinò L, Chiari R and Metro G: Long noncoding RNAs: New insights into non-small cell lung cancer biology, diagnosis and therapy. Med Oncol 33: 18, 2016.

18. Prensner JR and Chinnaiyan AM: The emergence of lncRNAs in cancer biology. Cancer Discov 1: 391-407, 2011.

19. Jin C, Peng X, Xie T, Lu X, Liu F, Wu H, Yang Z, Wang J, Cheng $\mathrm{L}$ and $\mathrm{Wu} \mathrm{N}$ : Detection of the long noncoding RNAs nuclear-enriched autosomal transcript 1 (NEAT1) and metastasis associated lung adenocarcinoma transcript 1 in the peripheral blood of HIV-1-infected patients. HIV Med 17: 68-72, 2016.

20. Yang Y, Cai Y, Wu G, Chen X, Liu Y, Wang X, Yu J, Li C, Chen X, Jose PA, et al: Plasma long non-coding RNA, CoroMarker, a novel biomarker for diagnosis of coronary artery disease. Clin Sci 129: 675-685, 2015.

21. Zhou X, Yin C, Dang Y, Ye F and Zhang G: Identification of the long non-coding RNA H19 in plasma as a novel biomarker for diagnosis of gastric cancer. Sci Rep 5: 11516, 2015.

22. Zheng K, Dou Y, He L, Li H, Zhang Z, Chen Y, Ye A, Liu W and Kong L: Improved sensitivity and specificity for prostate cancer diagnosis based on the urine PCA3/PSA ratio acquired by sequence-specific RNA capture. Oncol Rep 34: 2439-2444, 2015.

23. Sun M, Song J, Zhou Z, Zhu R, Jin H, Ji Y, Lu Q and Ju H: Comparison of serum microRNA21 and tumor markers in diagnosis of early non-small cell lung cancer. Dis Markers 2016: $3823121,2016$.

24. Chen F, Li WM, Wang DM, Gao SS, Bao Y, Chen WB and Liu D: Clinical value of combined detection of serum tumor markers in lung cancer diagnosis. Sichuan Da Xue Xue Bao Yi Xue Ban 39: 832-835, 2008 (In Chinese).

25. Shi X, Sun M, Liu H, Yao Y, Kong R, Chen F and Song Y: A critical role for the long non-coding RNA GAS5 in proliferation and apoptosis in non-small-cell lung cancer. Mol Carcinog 54 (Suppl 1): E1-E12, 2015.

26. Tong YS, Wang XW, Zhou XL, Liu ZH, Yang TX, Shi WH, Xie HW, Lv J, Wu QQ and Cao XF: Identification of the long non-coding RNA POU3F3 in plasma as a novel biomarker for diagnosis of esophageal squamous cell carcinoma. Mol Cancer 14: 3, 2015.

27. Shao Y, Ye M, Jiang X, Sun W, Ding X, Liu Z, Ye G, Zhang X, Xiao B and Guo J: Gastric juice long noncoding RNA used as a tumor marker for screening gastric cancer. Cancer 120: 3320-3328, 2014

28. Yang-Chun F, Min F, Di Z and Yan-Chun H: Retrospective study to determine diagnostic utility of 6 commonly used lung cancer biomarkers among Han and Uygur population in Xinjiang Uygur Autonomous Region of People's Republic of China. Medicine (Baltimore) 95: e3568, 2016.

29. Ma L, Bajic VB and Zhang Z: On the classification of long non-coding RNAs. RNA Biol 10: 925-933, 2013.

30. Malih S, Saidijam M and Malih N: A brief review on long noncoding RNAs: a new paradigm in breast cancer pathogenesis, diagnosis and therapy. Tumour Biol 37: 1479-1485, 2016.

31. Peng L, Yuan X, Jiang B, Tang Z and Li GC: LncRNAs: key players and novel insights into cervical cancer. Tumour Biol 37: 2779-2788, 2016

32. Yang Q, Zhang RW, Sui PC, He HT and Ding L: Dysregulation of non-coding RNAs in gastric cancer. World J Gastroenterol 21: 10956-10981, 2015.

33. Roberts TC, Morris KV and Wood MJ: The role of long non-coding RNAs in neurodevelopment, brain function and neurological disease. Philos Trans R Soc Lond B Biol Sci 369: 369, 2014.

34. Lorenzen JM and Thum T: Long noncoding RNAs in kidney and cardiovascular diseases. Nat Rev Nephrol 12: 360-373, 2016.

35. Ferreira LB, Palumbo A, de Mello KD, Sternberg C, Caetano MS, de Oliveira FL, Neves AF, Nasciutti LE, Goulart LR and Gimba ER: PCA3 noncoding RNA is involved in the control of prostate-cancer cell survival and modulates androgen receptor signaling. BMC Cancer 12: 507, 2012. 
36. Cui Y, Cao W, Li Q, Shen H, Liu C, Deng J, Xu J and Shao Q Evaluation of prostate cancer antigen 3 for detecting prostate cancer: A systematic review and meta-analysis. Sci Rep 6: 25776, 2016.

37. Konishi H, Ichikawa D, Yamamoto Y, Arita T, Shoda K, Hiramoto H, Hamada J, Itoh H, Fujita Y, Komatsu S, et al: Plasma level of metastasis-associated lung adenocarcinoma transcript 1 is associated with liver damage and predicts development of hepatocellular carcinoma. Cancer Sci 107: 149-154, 2016.

38. Li Q, Shao Y, Zhang X, Zheng T, Miao M, Qin L, Wang B, Ye G, Xiao B and Guo J: Plasma long noncoding RNA protected by exosomes as a potential stable biomarker for gastric cancer. Tumour Biol 36: 2007-2012, 2015.

39. Schneider C, King RM and Philipson L: Genes specifically expressed at growth arrest of mammalian cells. Cell 54: 787-793, 1988.

40. Mourtada-Maarabouni M, Hasan AM, Farzaneh F and Williams GT: Inhibition of human T-cell proliferation by mammalian target of rapamycin (mTOR) antagonists requires noncoding RNA growth-arrest-specific transcript 5 (GAS5). Mol Pharmacol 78: 19-28, 2010.

41. Tani $\mathrm{H}$, Torimura $\mathrm{M}$ and Akimitsu $\mathrm{N}$ : The RNA degradation pathway regulates the function of GAS5 a non-coding RNA in mammalian cells. PLoS One 8: e55684, 2013.

42. Mourtada-Maarabouni M, Hedge VL, Kirkham L, Farzaneh F and Williams GT: Growth arrest in human T-cells is controlled by the non-coding RNA growth-arrest-specific transcript 5 (GAS5) J Cell Sci 121: 939-946, 2008.

43. Ren S, Wang F, Shen J, Sun Y, Xu W, Lu J, Wei M, Xu C, Wu C, 'Zhang $\mathrm{Z}$ et al: Long non-coding RNA metastasis associated in lung adenocarcinoma transcript 1 derived miniRNA as a novel plasma-based biomarker for diagnosing prostate cancer. Eur J Cancer (Oxford) 49: 2949-2959, 2013.

44. Han L, Ma P, Liu SM and Zhou X: Circulating long noncoding RNA GAS5 as a potential biomarker in breast cancer for assessing the surgical effects. Tumour Biol 37: 6847-6854, 2016.

45. Schwarzenbach H, Hoon DS and Pantel K: Cell-free nucleic acids as biomarkers in cancer patients. Nat Rev Cancer 11: 426-437, 2011.

46. Stroun M, Maurice P, Vasioukhin V, Lyautey J, Lederrey C, Lefort F, Rossier A, Chen XQ and Anker P: The origin and mechanism of circulating DNA. Ann NY Acad Sci 906: 161-168, 2000 .
47. Yang Y, Shao Y, Zhu M, L Q, Yang F, Lu X, Xu C, Xiao B, Sun Y and Guo J: Using gastric juice lncRNA-ABHD ${ }_{11}$-AS1 as a novel type of biomarker in the screening of gastric cancer. Tumour Biol 37: 1183-1188, 2016

48. Chen G, Wang J and Cui Q: Could circulating miRNAs contribute to cancer therapy? Trends Mol Med 19: 71-73, 2013.

49. Yang T, Zeng H, Chen W, Zheng R, Zhang Y, Li Z, Qi J, Wang M, Chen T, Lou J, et al: Helicobacter pylori infection, $\mathrm{H} 19$ and LINC00152 expression in serum and risk of gastric cancer in a Chinese population. Cancer Epidemiol 44: 147-153, 2016.

50. Zhang K, Luo Z, Zhang Y, Zhang L, Wu L, Liu L, Yang J, Song X and Liu J: Circulating lncRNA H19 in plasma as a novel biomarker for breast cancer. Cancer Biomark 17: 187-194, 2016.

51. Zhang M, Guo H, Zhao S, Wang Y, Yang M, Yu J, Yan Y and Wang Y: Efficacy of epidermal growth factor receptor inhibitors in combination with chemotherapy in advanced non-small cell lung cancer: A meta-analysis of randomized controlled trials. Oncotarget 7: 39823-39833, 2016.

52. Greenhalgh J, Dwan K, Boland A, Bates V, Vecchio F, Dundar Y, Jain $P$ and Green JA: First-line treatment of advanced epidermal growth factor receptor (EGFR) mutation positive non-squamous non-small cell lung cancer. Cochrane Database Syst Rev 5: CD010383, 2016.

53. Cheng N, Li X, Zhao C, Ren S, Chen X, Cai W, Zhao M, Zhang Y, $\mathrm{Li}$ J, Wang Q, et al: Microarray expression profile of long noncoding RNAs in EGFR-TKIs resistance of human non-small cell lung cancer. Oncol Rep 33: 833-839, 2015.

54. Wang Y, Chen W, Chen J, Pan Q and Pan J: LncRNA expression profiles of EGFR exon 19 deletions in lung adenocarcinoma ascertained by using microarray analysis. Med Oncol 31: 137, 2014.

55. Dong S, Qu X, Li W, Zhong X, Li P, Yang S, Chen X, Shao M and Zhang L: The long non-coding RNA, GAS5, enhances gefitinib-induced cell death in innate EGFR tyrosine kinase inhibitor-resistant lung adenocarcinoma cells with wide-type EGFR via downregulation of the IGF-1R expression. J Hematol Oncol 8: 43, 2015. 